\title{
Legislative initiatives in the media: strategies for representation and interpretation
}

\author{
Valery M. Amirov*, Tatiana A. Glebovich \\ Faculty of Journalism, Ural Federal University, Lenina st., 51, Yekaterinburg, Russia
}

\begin{abstract}
The discussion of legislative initiatives, as well as the interpretation a legislative acts or amendments, is an ambiguous phenomenon within the framework of a thematic media discourse. The specified reason determines that the study of the phenomenon is a necessary and relevant thing. The analysis of a legislative hypertext involves the consideration of representative and interpretive strategies of submission of laws by media. An approach seems relevant because the media shapes the public opinion and legal culture, ensures the quality and results of the public discussion of legislative innovations. The research of socio-legal communications is based on the methodology of critical discourse analysis involving the consideration of an unobvious purpose, structure, and additional meanings of the statement. The differences between the practices of representing legal decisions and interpreting lawmaking allowed singling out key strategies for the formation of legislative discourse. The official media represent a law or legislative initiative using strategies such as discussion and popularization, propaganda of law as the basis of society, education that raises the level of legal culture of the population. Opposition media practice the interpretation of legislative activity using other strategic decisions: constructive criticism, analysis of the development and adoption process, construction of a hypothesis of application, as well as emotional (provocative) interpretation.
\end{abstract}

\section{Introduction}

The discussion of legislative initiatives is an obvious part of the analytical agenda of the media, because, according to M. Davydova's definition, Federal laws are "official sources of generally binding rules of conduct issued by competent authorities" [1]. At the same time the interpretations of the problem of the federal law or amendment is an ambiguous phenomenon in the framework of the thematic media discourse. These reasons determine the necessity and relevance of the study of the phenomenon.

The process of shaping the legislative discursive space implies the consideration of representational and interpretive strategies in dynamics and development. This approach seems relevant because "the media form the legal culture of the population continuously, while other subjects make such impact urgently, periodically or irregularly" [2].

The research analysis of public-legal communications is based on the concept of "legal journalism", introduced by O. V. Tretyakova [3]. The latter is understood as "subject-thematic specialization aimed at reflecting the legal life of society in the media, at disseminating information about specific legal facts, events and phenomena" [ibid]. According to researchers, the internal classification of the concept includes a few structural elements. They are "Dissemination of general information about legislation ... Judicial publicism ...
Criminal chronicle ... Moral and legal propaganda ... Legal advice" [4]. And the global goal of legal journalism is the formation of the legal culture of society [5], i.e. increasing "the level of legal awareness, as well as legal activity of society" [6].

In the ideal format of state-society communication, the media are called upon to promote "a model of lawabiding behavior into the public consciousness as a socially approved model" [7]. In the discursive media space, the opposite processes often develop. The works emphasize that the so-called "collective authorship" of interpretive texts generates a special cognitive environment that forms a system of public perceptions [8], and the redundancy of estimates and points of view transforms the content of the original legal text [ibid]. Accordingly, the purpose of this article is to analyze the main strategies of representation and interpretation of laws by the socio-political media of different political orientations.

This practical and research problem determines the appeal to the resources of discourse analysis and modern discourse studies as a theoretical and methodological basis.

The term "discourse", introduced into scientific circulation by French philosopher M. Foucault, has many interpretations. It often denotes "a set of statements" subordinated to "the same system of formation" [9]. It is actively used and developed in the works of several European and Russian scientists. T.A. 
van Dijk proposes to understand the term "discourse" as "a completed or continuing product" of a communicative action, its written or oral result, which is interpreted by the recipients [10]. The methodology of critical discourse analysis implies "focusing on the use of language (discourse as a special dimension of the political domain) and those non-obvious political implications that are behind a seemingly neutral medium" [11].

The empirical basis of the work was media publications of various types, devoted to the most highprofile legislative initiatives and decisions of the late 2020 and early 2021.

\section{Analysis of media materials}

The process of reviewing the empirical material is built on the reference to pro-government and neutral media outlets, as well as those with an oppositional concept at their core.

The Education Law was one of the high-profile phenomena on the legal agenda. We selected eight out of more than fifty publications.

Pro-government and neutral media outlets preface their publications with neutral, factual headlines: "Putin signed the law on educational activity" (the headline is identical in the two publications); "Education without a license will be forbidden". The polemical headers are also present without any subtext or additional emotional content: "Will the propaganda activities die out". The subject of the discussion is stated discreetly. In the publications of "Izvestia" and "Regnum", the representation of the law is limited to the informational report and the statement of the fact.

The federal newspaper "Expert" and the regional newspaper "Oblastnaya Gazeta" use roughly the same scheme of presentation: they explain the concepts introduced by the law, citing references, and then present various points of view, including critical ones. Despite the considerable depth of critical arguments and their logical structure, the controversy does not look sharp. The opinions of experts are presented without stating their personal position. The obvious debatability of the subject is smoothed out, and the format of the discussion is emphasized neutrality. The mentioned characteristics allow us to speak about the strategy of the discussion as a leading communicative solution in the process of presenting the law.

Opposition publications offer a different approach to the topic. The Fontanka.ru article "Pants on with the permission of the Interior Ministry" also features a scheme from statement to polemic, but with a different content. The excerpt from a quote by S. Witte used as the title predetermines the publication's critical in content and ironic in form position with regard to the subject of the discussion.

The extensive quotation of the discussing parliamentarians should be constructive by definition. But within the standard exchange of opinions there is a break in the communicative pattern. The statements of KPRF deputy Oleg Smolin are based on thematically significant cultural and political background. The images of cultural and political figures (A. Blok, S. Witte) included in the polemic and associative links with precedent historical events demonstrate the depth of the problem and create considerable potential for interpretation in the quoted statement: The authors of the bill, in the spirit of Benckendorff or Pobedonostsev, see enlightenment rather than evil. As Blok wrote, "Pobedonostsev spread his owl's wings over Russia". As a result, an additional problematic of the publication, related to the repetition of historical and political scenarios, is formed.

The title of "Novaya Gazeta's" article, "Education Fighters: A Touch for a Group Portrait" states a sharply critical and irreconcilable stance on the subject. At the same time, the subtitle "Or Why Deputies Vote for Laws They Don't Support" poses an additional, no less acute problem. The structure of the titled material differs significantly from those discussed earlier. The author, Leonid Gozman, cursorily formulates the background to the question (the historical dispute between the intelligentsia and the authorities in the context of state myth making). And then he moves on to the unambiguous and aggressive, from the point of view of communication strategy, thesis and the rigid system of evidence: Everything is also clear with those who, by direct order, or by guessing the wishes of the rulers, promote insane and brutal laws and prohibit all living things. They are criminals. It is unlikely that they will ever be tried, but this does not change the matter - they are criminals.

The marked structure of the material solves several problems at once. It presents the author's position, indicates the direction of journalistic analysis (the study of the practice of creation and adoption of legislative initiatives). It also forms additional problems and the context [12] of the adoption of the law, associated with the personal qualities and career scenarios of representatives of the parliamentary body. The adopted law itself is interpreted not as a tool for implementing political decisions, but as a product of the functioning of the society of power and the models of personal behavior adopted in it. The identified specifics of the public representation of the law and its subsequent interpretation expands and deepens the problematic thematic field.

The article "The Government Wants to Introduce Severe Restrictions on Educational Activities Under the New Law" published on the "It's my City" portal examines the new law in a way that proceeds from its reference to a document and terms to its interpretation. First of all, the reader's attention is focused on the system of requirements now imposed on participants in educational public communication, on the key concept of the law ("educational activity") and the list of bans to be introduced.

A parallel analysis of the non-obvious wording of the law in terms of the content and the reference to the lack of experience in applying this kind of legislative decisions form a certain media image of the event. Moreover, the subtitle "Violation of freedom of speech" introduces an unambiguous assessment. In terms of 
communication characteristics, we can conclude about the interpretation of the legal event, based on the strategy of creating a hypothesis of the application of the new law and the analysis of predictive results.

The law on punishment for insulting veterans is also presented in the media of different typological affiliations. In the media representation of the named document, the differences between the media strategies of different types are expressed to a lesser extent. Almost all media outlets supporting the official point of view made headlines about increased punishment for certain actions: "The Duma passed a law to punish insulting veterans. Putin signed a law to punish insulting veterans. Putin signed a law to increase punishment for insulting veterans. The Duma passed laws on fines and imprisonment for insulting veterans".

The materials themselves are constructed as a commentary on repressive mechanisms, using a significant number of citations. "Izvestia" and "RBC" supplemented their materials with a brief review of the precedent situation - the content of the charges against opposition politician Alexei Navalny, while "Rossiiskaya Gazeta" focused readers' attention on Vyacheslav Volodin's quote about the need to expand the law into international practice. In this case, we can hardly talk about the diversity of communicative strategies for presenting the law, but rather about the forms of stating the fact of legislative changes and approaches to commenting on them.

Opposition publications reacted with restraint in the presented case. As in the government's case, the emphasis was placed on the representation of the content of the introduced changes, the legal consequences of violations of the new law, and the precedent judicial situation (the Navalny trial). "Novaya Gazeta" expressed apprehension over the application of the law to groups of persons considered equal to veterans, as well as over research activities: This is already a witch hunt: first of all, against those who allow themselves to speak with historical facts in their hands about the price the USSR had to pay for the victory as a result of Stalin's mistakes and crimes. "Fontanka" published an interview with one of the authors of the bill, Michael Emelyanov. This material analyzes the process of development and adoption of the law, implementing the strategy of interpretive communication within the framework of the topic.

The law on pre-installation of Russian software on all devices without exception caused numerous media reactions. The media supporting the official point of view implement two communication strategies: "Rossiyskaya Gazeta" and "Izvestia" state the fact of the adoption of the new law and inform their readers about it. Informative, neutral headlines are used, for example: "A ban on the sale of equipment without domestic software came into force in the Russian Federation". The "Rossiyskaya Gazeta" draws the attention of the audience to the gradual introduction of new norms and the postponement of the date of penalties for the lack of mandatory software.

The key information is put in the headline: "The introduction of fines for the sale of gadgets without
Russian software may be postponed", its task is to demonstrate the loyal position of the state in relation to manufacturers and sellers. In turn, "Regnum" sets itself educational objectives. The agency's material is titled "How will the "law banning the sale of electronic equipment" work in Russia". The strategy of enlightening explanation is implemented in the text of the publication. An information technology specialist, together with a journalist, gives a detailed commentary of a legal event. "Tsargrad TV", like the first two publications, presents the introduction of the new law and supplements its publication with minimal commentary by experts.

Opposition media reacted ambiguously. "Novaya Gazeta" and "Fontanka" chose a strategy of the conflicting interpretation, which unfolded with the headlines: "Fuflosoft for your smartphone", "We got another law that won't be executed". Both publications used strategies of constructive criticism and forecasting, revealing the internal mechanisms of application of the new law.

The results of conflicting interpretations differ significantly. "Novaya Gazeta" proposes to dwell on the problems of lobbying the interests of Russian software developers in the Duma, and the introduction of new propaganda messages. "Fontanka" gives the floor to several representatives of the expert community and uses their statements to model the practice and problems of enforcing the new legislative act. Both communication solutions generate additional media stories and actualize the sociopolitical problems associated with the new law.

Other opposition media, in particular "Znak.com", present the implementation of the new legislative decision without interpretative content and an expressed authorial position, but with commentary from the business community, for example, in the article "In Russia the entry into force of the law on the preinstallation of domestic software on gadgets was postponed".

The presented point of view contains a negative assessment of the consequences of the law; it can be regarded as a forecasting strategy. In the material "Znak.com" this strategy is implemented in the framework of representational communication outside of the versatile disclosure of the related issues. Thus, it is possible to talk about a variety of communication solutions in the practice of publications with a similar political orientation.

The law on medical detoxification transforms the media representation of legal events. In this context, we can talk about similar strategies of official and opposition media. First of all, it is necessary to distinguish the representation of the legislative event based on the strategy of education.

A number of publications analyze the application of the new law, aiming to increase the legal culture of the audience, as well as to show the possible personal risks. It is instructive to compare the approaches of two media outlets that differ in all typological features: "Oblastnaya Gazeta" in the article "Vytreziteli Revisited" and "Novaya" in the article "Lie Down for Sobering Up". 
The first case presents a strategy of a detailed discussion of the new law in order to popularize its main ideas. For this purpose, comments by officials with various functions and powers and the opinion of the Human Rights Ombudsman are presented. Elements of constructive criticism of possible weaknesses in law enforcement are introduced into the discussion process, but consideration of possible distortions in legal practice only underscores the general urgency of introducing the new law. The presentation concludes with an unequivocally positive conclusion about the legislative event and an emphasis on its humanistic resource.

"Novaya Gazeta" presents legal changes in the genre of reporting from a specialized institution. The construction of the hypothesis of application is replaced by the representation of practice, and the audience's own assessment of the event is assumed. Interpretation is presented through the comments of participants in the social interaction regulated by law.

The word is given both to officials and to the people, to whom the application of the law is directed - the clients of the specialized institution (sobering-up facility). In this case, we can record the presence of the strategy of the emotionally marked interpretation. The material presents the situation, condition, opinions and emotions of people caught up in the application of the new law. Separate scenes with the characters, their statements represent the most problematic moments in the implementation of the new legislative initiative, demonstrating the imperfection of the legal framework of the law and the importance of the human factor in its implementation.

\section{Conclusions}

The identified differences between the practices of representation of legal decisions and interpretation of lawmaking within the discursive space allow us to identify key strategies. The media supporting the official point of view represent the signing of a new law or the discussion of a legislative initiative using the following strategies:

- Advocating law as the foundation of society and advocating specific laws that improve society.

- Discussion, which has two objectives: demonstration of the approval of the population (in synergy with the propaganda strategy) and promotion of the main ideas of the proposed legislation.

Education, carried out to raise the general level of the legal culture of the population and affirm in its consciousness the concept of the "rule-of-law state" (also in the interaction with the propaganda strategy).

Opposition media more often practice the interpretation of the legislative activity using the following strategic solutions:

constructive criticism - identifying ambiguous mechanisms of application of a new law or legal act, actualization and analysis of historical and foreign legal precedents and practices;

analysis of the process of development and adoption involves covering the stages of work on the bill: reconstruction of the process of proposing the initiative, its discussion, amendments, the study of the political background of the authors.

The construction of the hypothesis of application is aimed at modeling situations subject to new jurisdiction, involving experts, expert communities, as well as ordinary participants of social interaction.

Emotional (provocative) interpretation is associated with the intentions of the strategy of constructive criticism, designed to record the practice of application of the law from within, from the perspective of an ordinary participant of social and legal interaction.

The mentioned strategies solve a whole range of socially significant tasks in the field of education to increase the legal culture of the audience to maintain the format and tension of the media discussion related to the legal development of society.

\section{References}

1. M.L. Davydova, Formation and normalization of legal terminology in the field of digital technologies, Bulletin of Volgograd State University. Series 2, Linguistics, 4, 52-63 (2020). DOI: https://doi.org/10.15688/jvolsu2.2020.4.5

2. D. Martynkina, Legal education of the population through print media: history and modernity, Bulletin of Moscow University. Series 10. Journalism, 5, 7278 (2010)

3. O.V. Tretyakova, Journalism and the legal culture of society: interaction in the context of the development of democracy (doctoral dissertation). (St. Petersburg State University, St. Petersburg, 2012).

4. E.A. Berezina, Legal journalism in the modern media system, Bulletin of the RSUH. Series: Literary criticism. Linguistics. Cultural studies, 8, 144-152 (2010)

5. J.A. Smal, Legal topics in journalism, Bulletin of Voronezh State University. Series: Philology. Journalism, 2, 201-204 (2013)

6. V.S. Byalt, A.V. Demidov, Legal culture of society: theoretical and legal characteristics, Leningrad Legal Journal, 1(51), 19-25 (2018)

7. Fundamentals of the state policy of the Russian Federation in the field of the development of legal literacy and legal awareness of citizens (approved by President of the Russian Federation 28.04.2011 N Pr-1168).

8. S.V. Ineshina, Models of Interpretation of the Event in the Discourse of the Russian Press, Bulletin of Kemerovo State University, 2, 176-182 (2018). DOI: https://doi.org/10.21603/2078-8975-2018-2176-182.

9. M. Foucault, Diskurs and truth (Logos, 2008) 2, 162 p.

10. T.A. van Dijk, To the definition of discourse (London, 1998) 
11. K.A. Pahalyuk, Criticism of discourse: research programs and protest practice, Polis, 1, 157-174 (2018)

12. S.T. Nefedov, V.E. Chernyavskaya, Context in linguistic analysis: pragmatic and discursive- analytical perspective, Bulletin of Tomsk State University. Philology, 63, 83-97 (2020). DOI: $10.17223 / 19986645 / 63 / 5$. 